\section{Personalised, population and planetary nutrition for precision health}

Nutrition is a global science that originally was envisaged to biologically analyse and integrate the processes related to food transformation into energy and nutritious components for cell functions and homeostasis. ${ }^{1}$ Noteworthy, it is now evident that such physical, chemical and metabolic reactions participate in human development to ensure life expectancy and well-being, with a growing and inseparable relevance for personal, population and planetary health. ${ }^{2}$ Nowadays, nutritional challenges and nutritionist's interests are being focused on health and wellness involving physical, emotional, intellectual, cognitive, spiritual, environmental and occupational facets. ${ }^{3}$ Moreover, according to the newer emerging health scenarios, food intake should be assessed in relationship with social, satisfaction, satiety, security, safety and sustainable dimensions. In this context, two apparently alternative approaches, one derived from a global public health perspective and another derived from a precisionpersonalised nutrition paradigm, should be harmonised and deliberated since they are complementary to each other and as such, personalised, participative, preventive and predictive strategies are all needed in order to maintain a healthy status as well as to prevent and manage diseases. ${ }^{4}$

\section{PRECISION PERSONALISED NUTRITION}

The evolving notion about precision nutrition concerns personalised nutrition guidelines and tailormade dietary prescriptions for the prevention and treatment of obesity, diabetes, cardiovascular events and other chronic diseases. The management of metabolic impairments, inflammatory/haematological disturbances or neoplasia/tumorous diseases with nutritional approaches are needed for health maintenance as well as in clinical practice. ${ }^{5}$ In this context, precision nutrition not only considers an individual's genomic background and nutrient-gene interactions but also a thorough phenotyping evaluation, including family and personal clinical features, perinatal feeding programming and expectantly a wide spectrum of bioinformatic data concerning metabolic pathways. This last aspect involves omics strategies and high-throughput technologies such as metabolomics, proteomics, (epi) genomics or metagenomics related to macronutrients and micronutrients metabolic utilisation. ${ }^{6}$ Indeed, the conceptual framework describing precision nutrition is based on evaluating the interpersonal diversity caused by genetic/epigenetic differences, the environmental and lifestyle exposome heterogeneity, metagenomic variations in microbiota and objective behavioural/ psychological features with evident consequences for conjoint personal and population public health-related challenges and applications. Consequently, precision nutrition should contemplate the implementation of an efficient individualised nutritional status and assessment of strategies based on validated indices and metrics for metabolic care in every person, being not only restricted to patients suffering chronic diseases but also to healthy subjects. ${ }^{7}$ Thus, it is a good mandate to recognise individual's differences and to develop new genetic and transcriptomic indicators, inclusive of proteomic, lipidomic and metabolomic approaches and nutrigenomic and metagenomic tools related to nutrient metabolism. ${ }^{8}$

Nevertheless, personalised clinical and phenotypical features including one's own psychological/personality patterns, specific food allergies and intolerances, differential cultural, social and environmental backgrounds, drug side effects, personal dietary preferences as well as singular lifestyle and environmental factors such as cold weather or warm, and very warm climates need to be addressed for a robust precision nutrition and medical approaches. Regulatory issues are needed to be developed and implemented for a smooth growth of nutrition and personalised endeavours and methodologies, where important achievements, recommendations and challenges are expected for combining public and personal health benefits including ethical issues. ${ }^{9}$

\section{PRECISION POPULATION NUTRITION}

A number of policies and public efforts are being currently devoted to generate evidence for health promotion and disease risk reduction supported by food-based dietary guidelines (FBDG) in order to instruct populations about healthy dietary habits. ${ }^{10}$ These messages are better interpreted than nutrient intakes only and easier to make recommendations on primary prevention of noncommunicable diseases (NCDs) when they are based on Mediterranean dietary components and other regional foods from Oriental, Latin American and Indian diets with spices rich in bioactive compounds. ${ }^{11} 12$ Of equal importance are the traditional African foods and diets which have not received global dimensions even though these are rich in their diverse nutrient quality such as nutrients provided insect foods.

In any case, nutritional advices in different continents and regions seem to be comprehensively similar across countries such as to consume a variety of foods in balanced proportions including fruits and vegetables, whole grains, cereals, legumes and moderate animal-source products and limit high energy yielding sugary and fatty foods. The adverse impact of ultraprocessed foods and discretionary food consumption involving red and processed meats, added sugars, confectionery and other detrimental food ingredients need to be explicitly disclosed on the packaged food labels and scores following the dietary guidelines. ${ }^{13}$ On the contrary, some myths on fats, oils and nuts need to be dispelled, given the strong available scientific evidence of their cardiovascular benefits and the dangers of overconsumption beyond a level without proper exercise to metabolise them adequately in the body. ${ }^{14}$ 
Information sourced from the FBDG repository of the FAO or articulated by WHO reveals that FBDG are currently available for about 100 countries or regions, where the incorporation of bioactive compounds occurring on foods and the analysis of environmental sustainability information, climate change data and considerations to sociocultural factors and swiftly varying dietary tendencies are fairly documented..$^{15}$ It is not the intent of this article to serve as advise to different countries, but to highlight the parameters to be considered in nutrition and health of the population depending on the climate and the nature of agricultural nutritious products that they are growing and which are used within traditional food practices over thousands of years.

Furthermore, epidemiological investigations concerning the impacts of Japanese, Nordic, Latin American and Mediterranean diets or African, Indian and Oriental plant-based nutritional patterns on NCDs have positioned evidences with remarkable benefits in health outcomes and life expectancy compared with westernised food intake habits of high fatty food and meat-rich diets. ${ }^{16}$ Furthermore, some well-conducted trials such as PREDIMED or DASH and Diabetes Prevention Programs implemented in USA, Europe, China, India or Japan have confirmed the role of lifestyle and dietary practices on health maintenance or prevention/ management of obesity, diabetes and cardiovascular events. ${ }^{17}$

Additionally, specific populationoriented public health-nutrition communication should reflect the specific physiological needs across the life cycle, including infancy and pregnancy or lactation status, which require tailored nutritional supplies to balance particular nutrient requirements and to account for cultural and socioeconomic differences among areas, countries and regions. Of course, education, practical training and professional development for sustainable food systems and dietary practices need to consider differential personal and population profiles in the low-income and high-income

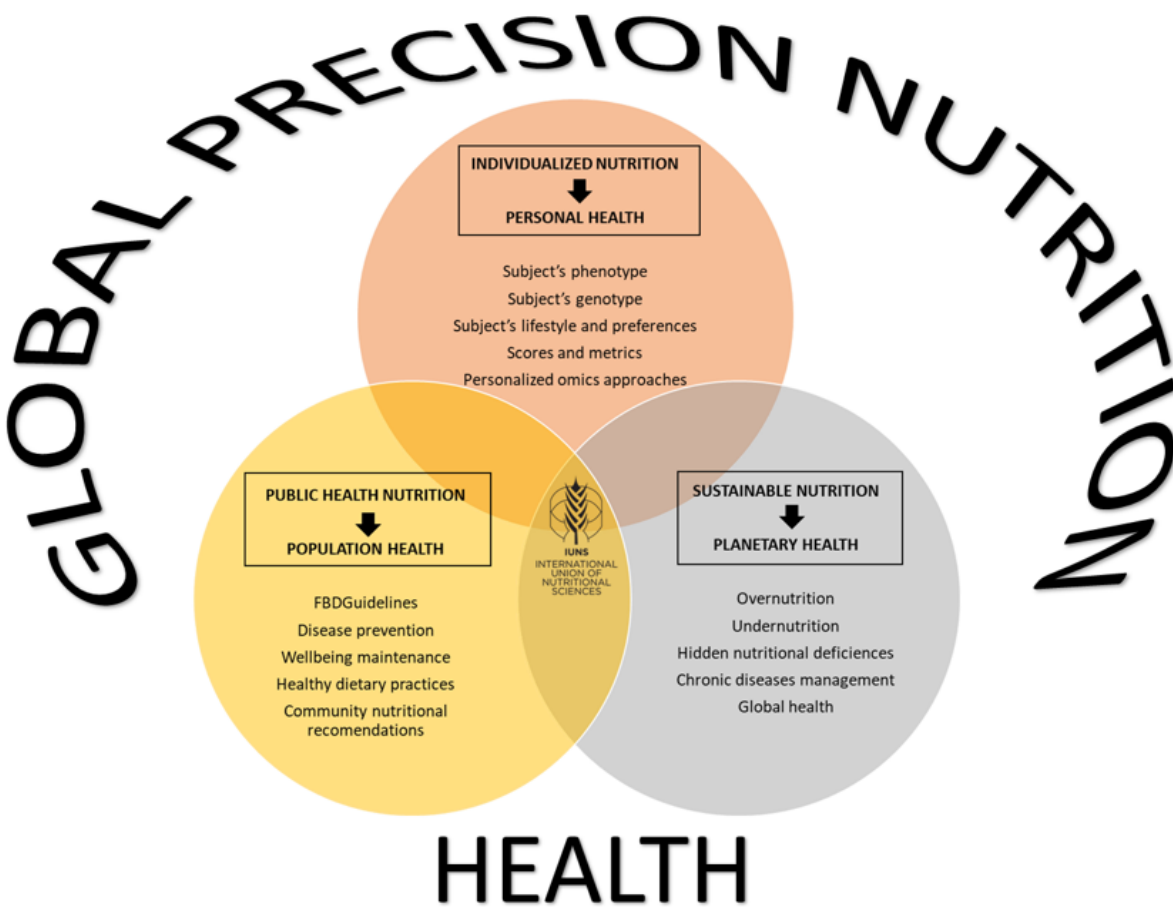

Figure 1 Schematic representation of global precision nutrition and its role in health from the perspective of linkages of nutrition to personal, population and planetary health respectively (based on IUNS task force).

countries and regions. ${ }^{18}$ Outstanding research and maintenance of large and long-term high-quality cohorts such as The European Prospective Investigation into Cancer and Nutrition, Framingham, The Supplementation en Vitamines et Mineraux Antioxydants, Nurses and Health Professionals and UK Biobank are important tools to develop/design policies and healthy messages for the people. These interventions need to be replicated with local modifications and food availability for sustainable nutrition agenda. New food frequency questionnaires and the implementation of appropriate biomarkers of food intake and surrogates of metabolic utilisation shall continue to improve our knowledge in a dynamic fashion. ${ }^{19}$

\section{PRECISION PLANETARY NUTRITION}

As stated in International Union for Nutritional Sciences (IUNS) vision declaration, to live a life without undernutrition is a fundamental human right, while nutrition improvement anywhere in the world is a societal, household and individual concern. Indeed, a major focus of planetary nutrition is to fight against the aetiological roots and hazardous consequences on health concerning the double burden of malnutrition, which involves not only undernutrition, stunting, underweight and wasting, including hidden deficiencies of micronutrients, but also excessive body weight and obesity, which are associated to a high impactful of NCDs across the globe. ${ }^{20}$ These endeavours should be based on concepts of sustainability, food security and environmental and climate change monitoring, which are receiving support and resources from important organisations and institutions such a UN agencies, UNICEF, FAO, WHO-OMS, World Bank, FMI and IUNS. Such attempts are also through integrated or independent initiatives such as GAIN, Scaling Up Nutrition, IUNS Task Forces and specifically via the WHO's Sustainable Development Goals. International embracing of a global nutrition agenda should address food and nutrition problems in developing countries as well as training/capacity building for nutritionists. The same is the situation with high-income countries and NCDs and the obesity pandemic. 
Current planetary challenges in nutrition include enhanced agricultural production for sustainable human development in order to match the planetary needs for nutrient intake. ${ }^{21}$ Socioeconomic and political issues controlling food distribution, food system transformation, food reformulations or discretionary taxes application to unhealthy dietary products, trade regulations concerning staple foods, the adoption of national/regional FBDG concerning healthy meal consumption such as vegetables, grains, legumes, cereals, seafood protein sources to fill in the nutritional gaps. ${ }^{22}$ The research of innovative and efficient dietary biomarkers and research metrics for nutritional surveillance are needed urgently and be complemented with sustainability factors on land and water use, climate change management and reduction in human-generated greenhouse gas emissions. It is only then when a friendly environment for mankind well-being with health and sustainability perspectives concerning global food consumption will emerge. ${ }^{23}$

In this context, precision, personalised, population and planetary nutrition for public health implementation must concentrate on promoting advancement in nutritional sciences, research and development through international cooperation at the global level (figure 1), where sustainable diets, nutrition in chronic diseases, infections and cancer, precision nutrition, risk and cost-benefit effectiveness of micronutrient interventions can be evaluated. It should also complement and supplement endeavours involving nutrient quality, food safety and attempts with global approaches for prevention and control of malnutrition, via traditional, indigenous and cultural foods and multidimensional indicators of child growth and development. ${ }^{24}$ Furthermore, novel approaches in nutrition programmes should encourage communication and collaboration among scientists as well as to disseminate information in nutritional sciences through modern communication virtual technologies aided by capacity building and online learning strategies accompanying a strong public health nutrition workforce. ${ }^{25}$ IUNS is making such attempts in this direction to reach out such knowledge networking spread globally, where phenotypical traits and the genetic makeup should be considered. ${ }^{26}$

\section{Precision nutrition conclusions}

Indeed, precision nutrition should deem all factors involved in global quality of life and metabolic wellbeing depending not only on the genotype but also on the dietary intake and associated healthy lifestyles in order to be worldwide developed and implemented in personalised, population and planetary settings for individual's, public and sustainable global health considering genetic and nongenetic-related phenotypes as well as environmental factors.

\section{Miguel A Martínez-González, ${ }^{1,2}$ Hyun-Sook Kim, ${ }^{3}$ Vish Prakash, ${ }^{4}$ Omar Ramos-Lopez, ${ }^{5}$ Francis Zotor, ${ }^{6}$ J Alfredo Martinez ${ }^{7,8}$}

${ }^{1}$ Department of Preventive Medicine and Public Health, University of Navarra, Pamplona, Spain

${ }^{2}$ Department of Nutrition, Harvard T H Chan School of Public Health, Boston, MA, USA

${ }^{3}$ Department of Food and Nutrition, Sookmyung

Women's University, Yongsan-gu, Seoul, The Republic of Korea

${ }^{4}$ Nutritional and Nutraceutical Research Centre, Ramaiah University of Applied Sciences, Bangalore, India

${ }^{5}$ Medicine and Psychology School, Autonomous University of Baja California, Tijuana, Mexico

${ }^{6}$ School of Public Health, University of Health and Allied Sciences, Ho, Ghana

${ }^{7}$ Precision Nutrition and Cardiometabolic Health, IMDEA-Food Institute, Madrid, Spain

${ }^{8}$ Biomedical Research Network Centre for

Pathophysiology of Obesity and Nutrition (CIBEROBN),

Carlos III Health Institute, Madrid, Spain

Correspondence to Professor J Alfredo Martinez, IMDEA, Madrid, Spain/IUNS;

jalfredo.martinez@imdea.org

Contributors JAM and MM-G planned and developed the editorial draft. All co-authors contributed, both conceptually and by providing an integrated vision of Nutrition as well as holistic nutritional perspectives around the world. All authors critically reviewed and approved the final version of the editorial. The current IUNS Council members (by alphabetical order) are: Benjamin Caballero, Ali Dhansay, Helmut Heseker, Catherine Geissler, Hyun-Sook Kim, J. Alfredo Martinez, Teruo Miyazawa, Lynnette Neufeld, Prakash V, Andrew Prentice and Francis Zotor.
Funding The authors have not declared a specific grant for this research from any funding agency in the public, commercial or not-for-profit sectors.

Competing interests None declared.

Patient consent for publication Not required.

Provenance and peer review Not commissioned; externally peer reviewed.

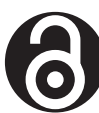
OPEN ACCESS

Open access This is an open access article distributed in accordance with the Creative Commons Attribution Non Commercial (CC BY-NC 4.0) license, which permits others to distribute, remix, adapt, build upon this work non-commercially, and license their derivative works on different terms, provided the original work is properly cited, appropriate credit is given, any changes made indicated, and the use is non-commercial. See: http://creativecommons.org/licenses/by-nc/4.0/.

C Author(s) (or their employer(s)) 2021. Re-use permitted under CC BY-NC. No commercial re-use. See rights and permissions. Published by BMJ.

\section{Check for updates}

To cite Martínez-González MA, Kim H-S, Prakash V, et al. Personalised, population and planetary nutrition for precision health. BMJ Nutrition, Prevention \& Health 2021; 4 :e000235

Received 13 January 2021

Accepted 18 May 2021

bmjnph 2021;4:e000235.

doi:10.1136/bmjnph-2021-000235

\section{REFERENCES}

1 Campbell TC. Nutritional renaissance and public health policy. J Nutr Biol 2017:3:124-38.

2 Hemler EC, Hu FB. Plant-Based diets for personal, population, and planetary health. Adv Nutr 2019;10:S275-83.

3 Kühn S, Rieger UM. Health is a state of complete physical, mental and social well-being and not merely absence of disease or infirmity. Surg Obes Relat Dis 2017;13:887.

4 Á GH. Retos actuales de la investigación en nutrición aplicada: ¿persona o población? [Current challenges of nutrition applied research: ¿person or population?]. Nutr Hosp 2018:35:39-43.

5 González-Muniesa P, Martínez JA. Precision nutrition and metabolic syndrome management. Nutrients 2019;11:2411.

6 Cornelis MC, Hu FB. Systems epidemiology: a new direction in nutrition and metabolic disease research. Curr Nutr Rep 2013;2:225-35.

7 Taberna DJ, Navas-Carretero S, Martinez JA. Current nutritional status assessment tools for metabolic care and clinical nutrition. Curr Opin Clin Nutr Metab Care 2019;22:323-8.

8 De Caterina R, Martinez JA, Kohlmeier M. Nutrigenetics and nutrigenomics. 
fundamentals of individualized nutrition. 1st edn. Academic Press Boca raton, 2019.

9 Kohlmeier M, De Caterina R, Ferguson LR, et al. Guide and Position of the International Society of Nutrigenetics/Nutrigenomics on Personalized Nutrition: Part 2 - Ethics, Challenges and Endeavors of Precision Nutrition. J Nutrigenet Nutrigenomics 2016;9:28-46.

10 Millen BE, Abrams S, Adams-Campbell L, et al. The 2015 dietary guidelines Advisory Committee scientific report: development and major conclusions. Adv Nutr 2016;7:438-44.

11 Martínez-González MA, Gea A, RuizCanela M. The Mediterranean diet and cardiovascular health. Circ Res 2019;124:779-98.

12 Schwingshackl L, Schwedhelm C, Hoffmann G, et al. Food groups and risk of all-cause mortality: a systematic review and meta-analysis of prospective studies. Am J Clin Nutr 2017;105:ajcn153148-1473.

13 Holdsworth M, Pradeilles R, Tandoh A, et al. Unhealthy eating practices of city-dwelling Africans in deprived neighbourhoods: evidence for policy action from Ghana and Kenya. Glob Food Sec 2020;26:100452.

14 Visioli F, Franco M, Toledo E, et al. Olive oil and prevention of chronic diseases: summary of an international Conference. Nutr Metab Cardiovasc Dis 2018;28:649-56.
15 Herforth A, Arimond M, Álvarez-Sánchez C, et al. A global review of food-based dietary guidelines. Adv Nutr 2019;10:590-605.

16 Galbete C, Kröger J, Jannasch F, et al. Nordic diet, Mediterranean diet, and the risk of chronic diseases: the EPIC-Potsdam study. BMC Med 2018;16:99.

17 Fitó M, Melander O, Martínez JA, et al. Advances in integrating traditional and Omic biomarkers when analyzing the effects of the Mediterranean diet intervention in cardiovascular prevention. Int J Mol Sci 2016;17:1469.

18 Wegener J, Fong D, Rocha C. Education, practical training and professional development for public health practitioners: a scoping review of the literature and insights for sustainable food system capacity-building. Public Health Nutr 2018;21:1771-80.

19 Mastrangelo A, Barbas C. Chronic diseases and lifestyle biomarkers identification by metabolomics. Adv Exp Med Biol 2017;965:235-63.

20 Wells JC, Sawaya AL, Wibaek R, et al. The double burden of malnutrition: aetiological pathways and consequences for health. Lancet 2020;395:75-88.

21 Caron P. Ferrero Y de Loma-Osorio G, Nabarro D, et al. food systems for sustainable development: proposals for a profound four-part transformation. Agron Sustain Dev 2018;38:41.
22 Springmann M, Spajic L, Clark MA, et al. The healthiness and sustainability of national and global food based dietary guidelines: modelling study. BMJ 2020;370:m2322.

23 Anand SS, Hawkes C, de Souza RJ, et al. Food consumption and its impact on cardiovascular disease: importance of solutions focused on the globalized food system: a report from the workshop Convened by the world heart Federation. $J$ Am Coll Cardiol 2015;66:1590-614.

24 Gil A, Martinez JA. Guide and proceedings of the International Union of nutritional sciences 21st international Congress of nutrition held in Buenos Aires, Argentina, 15-20 October 2017. Adv Nutr 2019;10:S1-3.

25 Delisle H, Shrimpton R, Blaney S, et al. Capacity-building for a strong public health nutrition workforce in low-resource countries. Bull World Health Organ 2017;95:385-8.

26 Ramos-Lopez O, Milton-Laskibar I, Martínez JA, et al. Precision nutrition based on phenotypical traits and the (epi) genotype: nutrigenetic and nutrigenomic approaches for obesity care. Curr Opin Clin Nutr Metab Care 2021. doi:10.1097/ MCO.0000000000000754. [Epub ahead of print: 14 Apr 2021]. 